\title{
Predictors of poor cardiac recovery pattern after aortic declamping in consecutive cardiac surgery cases.
}

\author{
Karmacharya $\mathrm{RM}^{1}$, Xigang $\mathrm{G}^{2}$, Jianjie $\mathrm{G}^{2}$, Haichen $\mathrm{W}^{2}$, Yang $\mathrm{Y}^{2}$, Yongxin $\mathrm{L}^{2}$ \\ ${ }^{1}$ Department of Surgery, Dhulikhel Hospital, Kathmandu University Hospital \\ ${ }^{2}$ Xian Jiaotong University, Xian, P. R. China
}

\begin{abstract}
Background

Poor Cardiac recovery following aortic declamping in cardiac surgery is associated with increased morbidity and mortality. This study aims to identify the predictors of poor cardiac recovery pattern after aortic declamping in consecutive cardiac surgery cases.
\end{abstract}

Methods

A prospective study was conducted from February 2011 to November 2011in elective cardiac surgical cases in First Affiliated Hospital of Medical College of Xi'an Jiaotong University. Single factor and subsequent logistic regression analysis was performed to identify the predictors of poor cardiac recovery pattern after aortic declamping.

Results

Of the 150 patients enrolled in the study, 38\% had good cardiac recovery while $62 \%$ had poor cardiac recovery after aortic declamping. Of the studied variables, those associated with significant outcome ( $P$ value $<0.05$ ) in all the subgroups were NYHA (New York Heart Association) classification ( 1 or 2 vs. 3 or 4) , Control group vs. blood cold cardioplegia, Route of cardioplegia, Age, Cardiopulmonary Bypass time groups, aortic clamping duration, ejection fraction and presence of pulmonary hypertension. From multivariate logistic regression analysis for predictors of cardiac recovery pattern, it was found that Age more than 40 years, NYHA category 3 or 4 , ejection fraction less than $55 \%$, aortic clamping time 60-120 minutes were significantly associated with poor cardiac recovery pattern. Cardiopulmonary bypass time however was not significantly associated as independent predictors of poor cardiac recovery pattern after aortic declamping.

\section{Conclusion}

Age more than 40 years, NYHA category 3 or 4 , ejection fraction less than 55\%, aortic clamping time $60-120$ minutes are independent predictors of poor cardiac recovery pattern after aortic declamping.

Key words cardiac recovery pattern, predictors, aortic declamping. 


\section{Introduction}

Since the first successful closure of Patent Ductus Arteriosus by Dr. Robert Gross in $1938^{1}$, cardiac surgery as a separate surgical entity has evolved well. Invention and refinement of Cardio pulmonary bypass (CPB) technology has made repair of wide varieties of cardiac conditions possible. ${ }^{2,3,4}$ With use of CPB technology, machine can temporarily overtake the function of heart while heart is made to stop beating. At the initiation of weaning from $\mathrm{CPB}$, after rewarming, the clamp on the aorta is taken out. With this, heart also takes part in pumping blood alongside CPB machine in parallel circuit. With aortic declamping, coronary perfusion ensues and heart begins to beat on its own. The way the heart begins to beat during this phase is termed as cardiac recovery pattern. Cardiac recovery pattern can be classified as good and poor based on two important factors. The first one is the way sinus rhythm is reverted (as spontaneous, with use of pacemaker, and with use of defibrillator). The second method is by noting the time taken to revert to sinus rhythm.

Although there is some scarcity on the studies of poor cardiac recovery pattern immediately following aortic declamping, the knowledge of which will benefit to decrease the morbidity and mortality of patients. After aortic declamping, ventricular fibrillation and other tachyarrhythmias are common. It has been found that in about $30-40 \%$ of cases ventricular fibrillation occurs. ${ }^{5}$ Metabolic changes during such fibrillation or the counter shock treatment may contribute to myocardial injury ${ }^{6}$. Knowing the high risk groups for poor cardiac performance recovery pattern helps in anticipating that and making adequate preventive and therapeutic measures to make the damage minimum and thus increasing the benefits of surgical procedure.

Multivariate logistic regression analysis is a statistical tool for analysis of multiple predictors to know about their relative influence on the outcome. Also they can be used to identify independent predictors for the outcome. 7,8

This study aims to delineate the factors that have impact on this recovery pattern after aortic declamping in cardiac surgical cases.

\section{Patients and Methods}

\section{Data source}

We conducted a prospective study of the cardiac surgical cases performed in the First affiliated hospital of Xi'an Jiaotong University, Xi'an, P. R. China during the time period of February 2011 to November 2011. Data in headings of general information of patient, history and examination, investigations, operative findings were recorded in set questionnaire. Patients with complex diagnosis, with diagnosis belonging to multiple group (e.g. septal disease as well as valvular heart diseae) were not included in the study. Similarly the patients undergoing emergency cardiac surgery or repeat cardiac surgery were excluded in the study. Blood cold cardioplegia has been used in all the cases except the control group.

\section{Explanatory variables}

Data on age of the patient, sex of the patient, diagnosis, operation, duration of illness, NYHA classification, blood pressure on admission, blood investigations ( $\mathrm{Na}, \mathrm{K}, \mathrm{Ca}$, Urea, Creatinine) were recorded. In Chest X-ray presence of filling of pulmonary conus and presence of cardiomegaly ( $>50 \%$ cardiothoracic ratio) will be noted. Presence of preexisting rhythm disturbance were identified from baseline ECG. From a preoperative echocardiogram, ejection fraction, fractional shortening and presence of pulmonary hypertension were noted. As most of the patients (with diagnosis other than coronary artery disease) were not subjected to Cardiac catheterization, presence of pulmonary hypertension were taken into consideration from trans thoracic echocardiography report as per guidelines of Task Force for the Diagnosis and Treatment of Pulmonary Hypertension of the European Society of Cardiology ${ }^{9}$. This guideline states that there is high likelihood of pulmonary hypertension if tricuspid regurgitation velocity is $>3.4 \mathrm{~m} / \mathrm{s}$, Pulmonary artery systolic pressure $0.50 \mathrm{~mm} \mathrm{Hg}$. Regarding presence of coronary artery disease, $>50 \%$ occlusion in one or more major coronary artery branch were adopted.

Regarding groups of diagnosis, there were four groups. Septal defects included congenital heart diseases such as Atrial Septal Defect, Ventricular Septal Defect, Patent Ductus Arteriosus. Valvular heart disease included diseases of any one or more heart valves. Coronary heart disease included disease of one or more coronary arteries undergoing on pump or off pump coronary bypass surgery.

The duration of anesthesia, surgery, CPB and aortic clamping time and type of anesthesia and cardioplegia were recorded intraoperatively.

\section{Study outcomes}

Cardiac performance recovery pattern is grouped into three headings as recovery to sinus rhythm being spontaneous, requiring pacing, and requiring defibrillation respectively. Similarly, the recovery pattern is also grouped based on time taken to return to spontaneous rhythm. 


\section{Cardiac recovery pattern classification:}

Cardiac recovery pattern was classified based on two outcomes. The first one was based on need of pacing and/ or defibrillation before return to sinus rhythm. Based on this parameter, the cardiac recovery pattern was classified into class $A 1$ (No need of pacing and defibrillation), class A2 (Need of pacing), class A3 (Need of defibrillation with/ without need of pacing).

The other classification was based on the time taken to return to sinus rhythm. The cardiac recovery pattern was classified into class B1(Less than 5 minutes taken for return to sinus rhythm), class B2 (5-10minutes taken for return to sinus rhythm, and class B3( More than 10 minutes taken for return to sinus rhythm). If the cardiac recovery pattern was both $\mathrm{A} 1$ and $\mathrm{B} 1$, then it was considered as good cardiac recovery(R1), while all other recovery pattern ( $A 2$ or $A 3$, and B2 or B3) were considered as poor cardiac recovery(R2).

\section{Statistical analysis}

Database collection were done in Microsoft access 2007 edition and statistical analysis was done in statistical software (version 13.0;SPSS, Inc;Chicago,IL). Initially single factor analysis was done on the proposed predictors. Based on this analysis variables were selected for multivariate logistic regression analysis to identify independent predictors of poor cardiac recovery pattern. The level of significance taken was $<0.05$.

\section{Results}

\section{Basic parameters:}

One hundred and fifty patients were enrolled in this study. Of them, $43 \%$ were patients with valvular disease, $30 \%$ with septal disease, $16.7 \%$ coronary artery disease and $10.3 \%$ with other diseases. The mean duration of illness was 5.3 years, mean age was 39.33 years. Regarding the intraoperative variables, the mean duration of cardio pulmonary bypass was 112.41 minutes, and that of aortic clamping duration was 73.98 minutes. Similarly, the mean time taken to regain sinus rhythm was 7.39 minutes, mean ejection fraction was $58.77 \%$ and mean fractional shortening was $30.38 \%$.

\section{Single-factor analysis results}

Among 150 patients 57cases (38\%), had good cardiac recovery pattern (R1 Group) while 93 cases (62\%) had poor cardiac recovery pattern. Table 1 shows the mean values of continuous variables in R1 and R2 groups. It was observed that the mean values of NYHA group, age, cardiopulmonary bypass and aortic clamping duration were higher in R2 group while mean ejection fraction was lower in $\mathrm{R} 2$ group and all these differences were significant at $P<0.05$.

Table 1: Mean values of continuous variables in R1 and R2 groups.

\begin{tabular}{|l|c|c|c|}
\hline Variables & $\begin{array}{l}\text { R1 Group/ Good } \\
\text { cardiac recovery } \\
\text { pattern (Mean) }\end{array}$ & $\begin{array}{c}\text { R2group/ Poor } \\
\text { cardiac recovery } \\
\text { pattern (Mean) }\end{array}$ & P Value \\
\hline Duration of illness & 6.20 & 4.85 & 0.205 \\
\hline NYHA classification & 1.82 & 2.32 & $\mathbf{0 . 0 0 0}$ \\
\hline Age & 27.30 & 46.71 & $\mathbf{0 . 0 0 0}$ \\
\hline $\begin{array}{l}\text { Duration of Cardio } \\
\text { Pulmonary Bypass } \\
\text { (Minutes) }\end{array}$ & 81.32 & 131.47 & $\mathbf{0 . 0 0 0}$ \\
\hline $\begin{array}{l}\text { Aortic Clamping } \\
\text { Duration (Minutes) }\end{array}$ & 44.65 & 91.96 & $\mathbf{0 . 0 0 0}$ \\
\hline $\begin{array}{l}\text { Ejection Fraction } \\
\text { (Percentage) }\end{array}$ & 60.77 & 57.54 & $\mathbf{0 . 0 4 8}$ \\
\hline $\begin{array}{l}\text { Fractional } \\
\text { Shortening }\end{array}$ & 31.01 & 29.98 & 0.375 \\
\hline
\end{tabular}

Table 2 shows the single factor analysis for predictors of poor cardiac recovery pattern. Of the studied variables, those associated with significant outcome ( $P$ value $<0.05)$ in all the subgroups were NYHA classification, control vs blood cold cardioplegia, route of cardioplegia, age, Cardiopulmonary Bypass time groups, aortic clamping duration, ejection fraction and presence of pulmonary hypertension. Presence of pulmonary hypertension however yielded beneficial effect on cardiac recovery pattern as the odds ratio is less than 1.

Table2: Single factor analysis for predictors of poor cardiac recovery pattern

\begin{tabular}{|c|c|c|c|c|c|c|}
\hline S.N. & Variable & Groups & $\begin{array}{l}\text { R1 (Good cardiac } \\
\text { recovery pattern) }\end{array}$ & $\begin{array}{l}\text { R2 (Poor cardiac } \\
\text { recovery pattern) }\end{array}$ & Odds ratio & $P$ value \\
\hline \multirow{4}{*}{1} & \multirow{4}{*}{ Diagnosis group } & Septal diseases & 29 & 16 & Ref & \\
\hline & & Valvular disease & 14 & 50 & 6.47 & $<0.01$ \\
\hline & & Coronary Artery Disease & 5 & 20 & 7.25 & $<0.01$ \\
\hline & & Other disease & 9 & 7 & 1.41 & 0.562 \\
\hline \multirow{3}{*}{2} & \multirow{3}{*}{ Duration } & Less than 1 year & 16 & 21 & Ref & \\
\hline & & $1-2$ years & 9 & 24 & 2.03 & 0.167 \\
\hline & & More than 2 years & 32 & 48 & 1.14 & 0.740 \\
\hline
\end{tabular}




\begin{tabular}{|c|c|c|c|c|c|c|}
\hline \multirow{2}{*}{3} & \multirow{2}{*}{ NYHA classification } & 1 or 2 & 53 & 62 & Ref & \\
\hline & & 3 or 4 & 4 & 31 & 6.625 & $<0.01$ \\
\hline \multirow{2}{*}{4} & \multirow{2}{*}{ Type of cardioplegia } & Control (No cardioplegia) & 17 & 5 & Ref & \\
\hline & & Blood cold & 40 & 88 & 7.480 & $<0.01$ \\
\hline \multirow{3}{*}{5} & \multirow{3}{*}{ Route of cardioplegia } & Control group (No cardioplegia) & 17 & 5 & Ref & \\
\hline & & Antegrade & 37 & 39 & 3.584 & $<0.05$ \\
\hline & & Both antegrade and retrograde & 3 & 49 & 55.533 & $<0.01$ \\
\hline \multirow{2}{*}{6} & \multirow{2}{*}{ Age } & $<40$ years & 39 & 27 & Ref & \\
\hline & & $>=40$ years & 19 & 66 & 5.296 & $<0.01$ \\
\hline \multirow{2}{*}{7} & \multirow{2}{*}{ Sex } & Female & 29 & 39 & Ref & \\
\hline & & Male & 28 & 54 & 1.434 & 0.286 \\
\hline \multirow{3}{*}{8} & \multirow{3}{*}{$\begin{array}{l}\text { Cardiopulmonary } \\
\text { Bypass Time Groups }\end{array}$} & Less than 60 minutes & 14 & 5 & Ref & \\
\hline & & $60-120$ minutes & 38 & 42 & 3.095 & $<0.05$ \\
\hline & & More than 120 minutes & 5 & 46 & 25.760 & $<0.01$ \\
\hline \multirow{4}{*}{9} & \multirow{4}{*}{$\begin{array}{l}\text { Aortic Clamping } \\
\text { duration }\end{array}$} & Control & 17 & 5 & Ref & \\
\hline & & Less than 60 minutes & 19 & 10 & 0.947 & 0.937 \\
\hline & & $60-120$ minutes & 20 & 62 & 5.580 & $<0.01$ \\
\hline & & More than 120 minutes & 1 & 16 & 28.80 & $<0.01$ \\
\hline \multirow{3}{*}{10} & \multirow{3}{*}{$\begin{array}{l}\text { Aortic Clamping } \\
\text { duration }\end{array}$} & Less than 60 minutes & 19 & 10 & Ref & \\
\hline & & $60-120$ minutes & 20 & 62 & 5.890 & $<0.01$ \\
\hline & & More than 120 minutes & 1 & 16 & 30.400 & $<0.01$ \\
\hline \multirow{2}{*}{11} & \multirow{2}{*}{$\begin{array}{l}\text { Ejection fraction } \\
\text { group }\end{array}$} & Normal i.e. $>55 \%$ & 47 & 55 & Ref & \\
\hline & & Low i.e. $<55 \%$ & 10 & 38 & 3.247 & $<0.01$ \\
\hline \multirow{2}{*}{12} & \multirow{2}{*}{ Fractional shortening } & Normal i.e. $>25 \%$ & 42 & 62 & Ref & \\
\hline & & Low i.e. $<25 \%$ & 15 & 31 & 1.400 & 0.367 \\
\hline \multirow{2}{*}{13} & \multirow{2}{*}{$\begin{array}{l}\text { Cardiomegaly in } \\
\text { Chest X-ray }\end{array}$} & Absent & 10 & 27 & Ref & \\
\hline & & Present & 47 & 66 & 1.923 & 0.116 \\
\hline \multirow{2}{*}{14} & \multirow{2}{*}{$\begin{array}{l}\text { Rhythm disturbances } \\
\text { in ECG }\end{array}$} & Absent & 10 & 10 & Ref & \\
\hline & & Present & 47 & 83 & 1.766 & 0.239 \\
\hline \multirow[b]{2}{*}{15} & \multirow{2}{*}{$\begin{array}{l}\text { Features of } \\
\text { Pulmonary } \\
\text { hypertension (From } \\
\text { echocardiography) }\end{array}$} & Absent & 23 & 63 & Ref & \\
\hline & & Present & 34 & 30 & 0.322 & $<0.01$ \\
\hline
\end{tabular}

\section{Multivariate logistic regression analysis results:}

Table 3 shows the results of logistic regression analysis. We conducted such analysis amongst five groups viz. NYHA category ( 1 or 2 vs 3 or 4), age, cardiopulmonary bypass time groups, aortic clamping duration groups and ejection fraction groups. All these groups had significant odds ratio with respect to the reference group. The two groups viz route of cardioplegia and features of pulmonary hypertension group, despite having significant odds ratio, were not included in logistic regression analysis results pertaining to fact that these results can be due to confounding factors as they contradicted with clinical experiences.

Table 3: Multivariate logistic regression analysis for predictors of cardiac recovery pattern

\begin{tabular}{|c|c|c|c|c|}
\hline Variable & Wald & S.E. & Odds ratio & Sig \\
\hline Age ( $>40$ years) & 5.924 & 0.441 & 2.927 & $<0.05$ \\
\hline NYHA (2 or 3$)$ & 4.613 & 0.683 & 4.332 & $<0.05$ \\
\hline $\begin{array}{l}\text { Cardiopulmonary bypass time gr } \\
\text { <60 minutes } \\
60-120 \text { minutes } \\
>120 \text { minutes }\end{array}$ & $\begin{array}{l}0.136 \\
3.253\end{array}$ & $\begin{array}{l}0.717 \\
0.897\end{array}$ & $\begin{array}{c}\text { Ref } \\
1.303 \\
5.044\end{array}$ & $\begin{array}{l}0.712 \\
0.071\end{array}$ \\
\hline $\begin{array}{l}\text { Aortic clamping time } \\
<60 \text { minutes } \\
60-120 \text { minutes } \\
>120 \text { minutes }\end{array}$ & $\begin{array}{l}7.703 \\
1.478\end{array}$ & $\begin{array}{l}0.509 \\
1.276\end{array}$ & $\begin{array}{c}\text { Ref } \\
4.108 \\
4.714\end{array}$ & $\begin{array}{l}<0.01 \\
0.224\end{array}$ \\
\hline Ejection fraction group (<55 \%) & 4.194 & 0.489 & 2.722 & $<0.05$ \\
\hline
\end{tabular}


From logistic regression analysis for predictors of cardiac recovery pattern, it could be inferred that Age more than 40 years, NYHA 2 or 3, ejection fraction less than 55\%, aortic clamping time 60-120 minutes were significantly associated with poor cardiac recovery pattern. Thus these four variables were independent predictors of poor cardiac recovery pattern after aortic declamping. Cardiopulmonary bypass time however could not be inferred significantly as independent predictors of cardiac recovery pattern.

\section{Discussion}

The present study is aimed to evaluate the independent predictors of cardiac recovery pattern in 150 patients undergoing cardiac surgery. Both mean duration of cardiopulmonary bypass and mean aortic clamping duration are increased in poor cardiac recovery group, and this difference is also found to be statistically significant $(P<0.01)$. The results of multivariate logistic regression analysis suggest that age more than 40 years, NYHA 2 or 3 , ejection fraction less than $55 \%$, aortic declamping time 60-120 minutes are independent predictors of poor cardiac recovery pattern. Compared to cardiopulmonary bypass time, aortic clamping time is observed to be a robust parameter for cardiac recovery pattern.

Many studies have found that the factors with profound impact on cardiac recovery pattern following cardiopulmonary bypass were low ejection fraction, older age, cardiac enlargement, female sex, the length of cardiopulmonary bypass and the duration of aortic crossclamping. ${ }^{10,11,12,13}$ However cardiac enlargement and female sex could not be well associated with poor recovery pattern in present study. Although need of ionotropic agents and the dose of the drug were commonly used to categorize cardiac recovery pattern, such categorization does consider the use of assisted (E.g. pacing, defibrillation) recovery and the duration taken to return to sinus rhythm after aortic declamping. ${ }^{14,15}$ Additionally ionotropic agents were given at separation from cardiopulmonary bypass machine and not immediately following aortic declamping.

Another common method of comparison is by noting difficulty in weaning from cardiopulmonary bypass. 16, 17 Francis Bernard et al concluded sex, diastolic dysfunction and total cardiopulmonary bypass time as independent predictor of difficult weaning from cardiopulmonary bypass. ${ }^{16}$ They have observed that the presence of diastolic dysfunction confers a fourfold increase in probability of needing inotropic or vasoactive drugs to separate from CPB. Length of ICU stay has also been used as comparing criteria for identification of predictor in different studies. ${ }^{18,} 19,20$ Low cardiac output syndrome is another such promishing factor that can be used as a category to identify predictors. 21,22 Manjula D. Maganti et al have found independent predictors of low cardiac output syndrome as renal failure, earlier year of operation, left ventricular ejection fraction $<40 \%$, shock, female gender and increasing age. ${ }^{22} \mathrm{~J}$. Ward Kennedy et al had compared predictors with operative mortality in Coronary Artery Surgery. ${ }^{23}$ Based on various prediction models, scoring system such as European system for cardiac operative risk evaluation (Euroscore), has also been created and widely being used to predict cardiac operative risk. However Parolari et al have found that these scoring systems have overestimation of mortality. ${ }^{24}$

In conclusion we have used a novel strategy to categorize cardiac recovery pattern. Large scale analysis of these factors within each groups of diagnosis is a matter of further interest and will be a part of our further research.

6. Praeger PI, Kay RH, Moggio R. Prevention of Ventricular Fibrillation after Aortic Declamping during Cardiac Surgery. Texas Heart Institute Journal 1988; 15:98-101.

7. QuX, Shrestha R, Wang Md. Risk Factors Analysis on Traumatic Brain Injury Prognosis. Chin Med Sci J 2011; 26 :98-102.

8. Ying C, Peng J, Peng KJ et al. An Introduction to Logistic Regression Analysis and Reporting. The Journal of Educational Research 2002; 96.

9. Galiè N, Hoeper MM, Humbert $M$ et al. Guidelines for the diagnosis and treatmentof pulmonary hypertension. European Heart Journal 2009; 30: 2493-2537.

10. Royster RL, Winston-Salem. Myocardial dysfunction following cardiopulmonary bypass: recovery patterns, predictors of inotropic need, theoretical concepts of inotropic administration. J Cardiothorac Vasc Anesth 1993; 7:19-25. 
11. Royster RL, Butterworth JF, Prough DS, et al. Preoperative and intraoperative predictors of inotropic support and longterm outcome in patients having coronary artery bypass grafting. Anesth Analg 1991;72:729-736.

12. Rao V, Ivanov J, Weisel RD, et al. Predictors of low cardiac output syndrome after coronary artery bypass. I Thorac Cardiovasc Surg 1996; 112:38-51.

13. Butterworth JF, Legault C, Royster RL, et al. Factors that predict the use of positive inotropic drug support after cardiac valve surgery.Anesth Analg 1998; 86:461-467.

14. Ahmed I, House CM, Nelson WB. Predictors of inotrope use in patients undergoing concomitant coronary artery bypass graft (CABG) and aortic valve replacement (AVR) surgeries at separation from cardiopulmonary bypass (CPB). J Cardiothorac Surg 2009; 4:24.

15. Kenneth H., David B. Schinderle, Madhav Swaminathan, Mihai V. Podgoreanu. Predictors of Inotrope Use During Separation From Cardiopulmonary Bypass. Journal of Cardiothoracic and Vascular Anesthesia 2004; 18: 404-408.

16. Bernard F, Denault A, Babin D et al. Diastolic Dysfunction is Predictive of Difficult Weaning from Cardiopulmonary bypass Anesth Analg 2001; 92: 291-298.

17. Hardy JF, Belisle S. Inotropic support of the heart that fails to successfully wean from cardiopulmonary bypass: the Montreal Heart Institute experience. J Cardiothorac Vasc Anesth 1993; 7:33-9.

18. Roelog G.A. Ettema, Linda M. Peelen, Marieke J. Schuurmans et al. Prediction Models for Prolonged Intensive Care Unit
Stay After Cardiac Surgery. Circulation 2010; 122:682-689.

19. Nashef SA, Roques F, Michel P, Gauducheau E et al. European system for cardiac operative risk evaluation (EuroSCORE). Eur J Cardiothorac Surg 1999; 16:9 -13.

20. Huijskes RV, Rosseel PM, Tijssen JG. Outcome prediction in coronary artery bypass grafting and valve surgery in the Netherlands: development of the Amphiascore and its comparison with the EuroSCORE. Eur I Cardiothorac Surg 2003; 24:741-749.

21. Rao V, Ivanov J, Weisel RD, et al. Predictors of low cardiac output syndrome after coronary artery bypass. J Thorac Cardiovasc Surg 1996;112:38 -51.

22. Manjula D. Maganti, Vivek Rao, Michael A. Borger, Joan Ivanov and Tirone E. David. Predictors of Low Cardiac Output Syndrome After Isolated Aortic Valve Surgery. Circulation 2005;112: 448-452.

23. Kennedy JW, Kaiser GC, Fisher LD, Fritz JK, Myers W, Mudd JG et al. Clinical and Angiographic Predictors of Operative Mortality from the Collaborative Study in Coronary Artery Surgery (CASS).Circulation1981; 63: 794-802.

24. Parolari A, Pesce LL, Trezzi M, Loardi C, Kassem S, Brambillasca C, Miguel B, Tremoli E, Biglioli P, Alamanni F. Performance of EuroSCORE in CABG and off-pump coronary artery bypass grafting: single institution experience and meta-analysis. Eur Heart J. 2009; 30:297-304. 